\title{
PRÁTICAS EDUCACIONAIS DISTINTAS: A PSICOLOGIA NO ENSINO MÉDIO PAULISTA
}

\author{
LUCIANA DADICO \\ Mestre e Doutoranda em Psicologia Escolar do Instituto \\ de Psicologia da Universidade de São Paulo \\ ludadico@usp.br
}

\begin{abstract}
RESUMO
Este artigo visa discutir, à luz da aprovação do Parecern. 38/06 do Conselho Nacional de Educação que torna obrigatório o ensino de Filosofia e Sociologia no ensino médio, a pertinência do ensino de Psicologia, em particular no Estado de São Paulo, onde esta disciplina vem progressivamente perdendo espaço. Subsidia o debate, pesquisa de caráter etnográfico, composta por dois estudos de caso realizados em estabelecimentos de ensino, um público e um privado, do município de São Paulo, onde foram acompanhadas aulas de Psicologia mediante observação e analisadas questões relativas ao ensino dessa disciplina. Aspectos característicos de cada escola levaram a refletir sobre as disparidades do sistema educacional paulista, conduzindo à discussão sobre o ensino de Psicologia e sua contribuição, como ciência, nesse cenário.

PSICOLOGIA - ENSINO - CURRÍCULO - ENSINO MÉDIO
\end{abstract}

\begin{abstract}
DIVERSE EDUCATIONAL PRACTICES: PSYCHOLOGY AT THE STATE OF SÃO PAULO HIGH SCHOOLS. The objective of this article is to discuss, in light of the approval of the Official Opinion number 38/06 by the National Council of Education which made teaching Philosophy and Sociology mandatory in high school, the relevance of teaching Psychology, particularly in the state of São Paulo, where this subject has been increasingly losing space. The debate is grounded in an ethnographic survey consisting of two case studies carried out in teaching institutions, one public and the other private, in the city of São Paulo. Psychology classes were attended, and observation of issues related to teaching it were analyzed. The characteristic aspects of each school has led us to reflect about the inequalities within the São Paulo state education system, and to discuss teaching Psychology and its contribution, as a science, in this setting.

PSYCHOLOGY - TEACHING - CURRICULUM - HIGH SCHOOL
\end{abstract}


O ensino de Psicologia no nível médio regular vigora como diretriz governamental, no Estado de São Paulo, desde a publicação, em 1983, de Resolução da Secretaria de Estado da Educação', que buscava reorganizar o sistema educacional de modo a adequá-lo à legislação federal em maior consonância aos valores democráticos que se recompunham com vigor no período final da ditadura militar, especialmente após o movimento das Diretas Já e o retorno das eleições livres em 1982.

O ensino da Psicologia antes extinto no ensino médio regular pela promulgação da Lei n. 5.692, de 197। (assim como o da Filosofia e Sociologia), deu lugar à disciplina Educação Moral e Cívica, de acordo com os preceitos da Doutrina de Segurança Nacional. Retorna, então, no período da abertura política, ao menos no Estado de São Paulo, como disciplina optativa, com a missão de "assegurar uma visão integrada de homem", pertinente às novas atribuições do cidadão sob a égide da democracia.

A luta pela reinclusão de duas disciplinas, Sociologia e Filosofia, no currículo mínimo obrigatório brasileiro prosseguiu com o processo de redemocratização, e culminou com a aprovação do Projeto de Lei Complementar que substituía o artigo 36 da Lei de Diretrizes e Bases - LDB - n. 9.394/96, instituindo a obrigatoriedade das disciplinas Filosofia e Sociologia no currículo do ensino médio. Após aprovado no Senado e na Câmara Federal, o Projeto foi contudo vetado, em outubro de 200 I, pelo então presidente Fernando Henrique Cardoso, sob a alegação de que a obrigatoriedade dessas disciplinas implicaria incremento orçamentário impossível de ser suportado por estados e municípios, e de que não haveria número suficiente de professores formados capazes de atender à nova demanda.

O ensino da Psicologia, não tendo sido em nenhum momento obrigatório como disciplina (tampouco a Filosofia e a Sociologia compareciam como disciplinas obrigatórias nos Parâmetros Curriculares do Ensino Médio - PCNEM -, de 1999, cujos conteúdos considerados necessários ao exercício

I. Resolução n. 236/83, que, na Parte II, em seu inciso 3.2.7., estabelece: "Qualquer que seja a modalidade de curso escolhida, deve-se assegurar a visão integrada de homem e mundo, na perspectiva das ciências humanas, fundamentais para a formação do homem crítico e participante. Assim, na Parte Diversificada, além da Filosofia, componente essencialmente formador, recomenda-se a inclusão, nessa parte, de componentes que também concorram para aquele objetivo, tais como, Sociologia, Psicologia e outros." 
da cidadania, conforme indicado no texto, poderiam ser diluídos nas demais disciplinas da área de humanidades, nem por legislação federal, nem estadual, o que vigorava até 2005 nas escolas do Estado de São Paulo era uma alternância entre as disciplinas de Filosofia, Sociologia e Psicologia: ao menos duas delas deveriam constar do currículo do ensino médio - a critério principalmente da diretoria da escola, das diretorias de ensino e da própria oferta de professores disponíveis para contratação.

Após a aprovação pelo Conselho Nacional de Educação - CNE -, em julho de 2006, do Parecer n. 38/06, que estabelecia em um ano o prazo para a inclusão das disciplinas de Filosofia e Sociologia no currículo das escolas públicas e privadas de ensino médio no Brasil, tal inclusão tornou-se obrigatória por meio da Lei n. I I.684, sancionada no dia 2 de junho de 2008. Com essa obrigatoriedade, a Psicologia, dantes já pouco presente nas grades curriculares das escolas, tem sido progressivamente excluída do ensino nesse nível, tendo restrita sua oferta didática aos níveis superiores.

Já na esteira da discussão de que daria guarida ao parecer do CNE, a Secretaria de Estado da Educação, ainda sob a batuta de Gabriel Chalita, promulgou, em janeiro de 2005, a Resolução SE n. 6/2005, que fixava duas aulas para a disciplina de Filosofia no primeiro ano do ensino médio, duas aulas de Sociologia no segundo ano, e duas aulas de qualquer das disciplinas Filosofia, Sociologia e/ou Psicologia no terceiro ano. A carga horária destinada à Psicologia encolheu também no currículo do ensino médio paulista. Importante dizer que a regra valia apenas para as escolas da rede estadual, ou seja, escolas municipais e, principalmente, escolas privadas, sempre estiveram fora da normativa, sendo submetidas, portanto, apenas ao Parecer CNE n. 38/06, e agora à Lei n. 1 $1.684 / 08$. Após a última mudança de governo no estado, a Resolução/SE n. 92/07, revogou as resoluções anteriores que tratavam da matéria, e a Psicologia deixou de ser nomeada como disciplina, desaparecendo das diretrizes para o ensino médio paulista. A ênfase passou a ser dada à Filosofia, obrigatória nos dois primeiros anos do ciclo, com 2 aulas semanais. No $3^{\circ}$ ano, de acordo com o artigo $4^{\circ}$ da Resolução/SE n. 92/07, inciso III, parágrafo 1, 6 aulas semanais, caracterizadas como de "apoio curricular" passaram a ser distribuídas pela direção da escola, desde que cada conjunto de 2 aulas contemple uma das diferentes áreas de conhecimento.

Importante esclarecer que também as escolas da rede estatual devem cumprir a normativa que obriga à inserção da Sociologia como disciplina, de 
modo que, cedo ou tarde, 2 dessas aulas deverão ser atribuídas para professores autorizados a lecionar Sociologia. Assim, restam 4 aulas semanais para $o$ $3^{\circ}$ ano do ensino médio (majoritamente aquele regular, visto que as aulas de educação de jovens e adultos - EJA - também têm sofrido com a redução do número de salas) para as quais, em algumas poucas escolas, professores de Psicologia ainda têm conseguido atribuição.

De acordo com a indicação do Conselho Estadual de Educação - Indicação/CEE n.53/2005, os professores licenciados em Psicologia podem lecionar, no que se refere ao ensino médio regular, exclusivamente a própria disciplina Psicologia, enquanto esta mesma disciplina pode ser ministrada por licenciados em Filosofia e Pedagogia. Demais disciplinas da área de Humanas, como Sociologia, História e Filosofia podem ser ministradas por profissionais de diferentes formações na área, exceção feita aos licenciados em Psicologia, desde que se comprove carga de estudo da matéria superior a 160 horas (o nome da disciplina deve constar do currículo de formação do professor, conforme orientação da Secretaria de Estado da Educação). De acordo com uma concepção de Pedagogia como técnica (Roman, 1999), licenciados em Pedagogia podem, desde que possuam licenciatura ou carga de estudos referentes à matéria afim, ensinar em quaisquer disciplinas de Humanidades.

Sem desconsiderar, portanto, que a exclusão da disciplina de Psicologia representa uma efetiva perda de postos para os professores que atuam hoje na rede, não é meu desejo, dada a relevância do tema, restringir esta discussão a seus aspectos corporativos. Focalizo a discussão sobre os significados do ensino de Psicologia sob o ponto de vista de sua pertinência como conteúdo curricular. Se a obrigatoriedade do ensino de Filosofia e Sociologia é considerada um avanço na promoção de uma formação mais humanista, em tempos de valorização da especialização tecnológica, a "excomunhão" da Psicologia nos leva a refletir a respeito de sua defesa como conteúdo adequado à formação em nível médio.

A primeira questão a ser abordada refere-se à própria trajetória da Psicologia brasileira. Se sua presença na educação brasileira desde o último século é ao mesmo tempo marcada pela irregularidade (de meios) e pela constância (de participação) (Azzi, Solligo, 2008), podemos dizer que ela também esteve frequentemente na berlinda do tecnicismo, em detrimento de uma visão crítica de homem, trafegando, sob uma visão positivista de ciência, tanto nas áreas Biológicas quanto nas Humanas. Obviamente não estou com esta assertiva 
fazendo uma defesa unilateral de linhas determinadas; bem sabemos que a Psicologia como ciência se funda em matrizes epistemológicas diversas, a ponto de não ser possível falar em paradigmas no caso da Psicologia (Carone, 2003). Não obstante, o fato de se alinhar a esta ou àquela área de conhecimento ou linha de saber não é garantia de uma produção teórico-crítica, desde que não possamos refletir para além de sua especificidade (Horkheimer, 1980). Outrossim, a oferta didática de uma Psicologia "aplicada" apontaria a discussão para uma direção bastante diversa daquela que está fundamentando a inclusão da Sociologia e da Filosofia no currículo do nível médio.

Em segundo lugar, sendo esse o objetivo da pesquisa apresentada a seguir, é importante refletirmos sobre como tem transcorrido o ensino de Psicologia no nível médio em algumas escolas do Estado de São Paulo. Nos moldes atualmente vigentes, esse ensino tem sido conduzido de modo absolutamente díspar nos diferentes contextos do sistema educacional. Nesse sentido, pretendo apoiarme em observações realizadas em dois estabelecimentos de ensino paulistas.

\section{A PESQUISA}

A pesquisa compreendeu ao todo 43 horas de observação de aulas de Psicologia no ensino médio e foi realizada em duas escolas: 13 horas, em um estabelecimento de ensino particular, e 30 horas em um estabelecimento da rede pública de ensino, ambos na zona oeste do município de São Paulo, entre agosto e novembro de 2006. A escolha das escolas, referidas neste artigo por A e B respectivamente, foi aleatória. No caso da escola $A$, busquei espontaneamente contato com a coordenação pedagógica que me encaminhou para a professora de Psicologia, a qual, por ter perdido um estagiário, poderia abrigar-me sem interferência espacial nas salas de aula (sempre lotadas, com apenas uma cadeira vaga, que passei a ocupar). No caso da escola B, tratava-se de estabelecimento onde eu já atuara anteriormente como estagiária de disciplina do curso de licenciatura em Psicologia; bastou um novo contato com a direção e com a professora de Psicologia, que não ofereceram resistência à minha presença na escola. Apesar da observação nas escolas ter acontecido em um período de tempo bastante restrito - o que inviabilizaria intervenções maiores em campo, nos moldes de uma pesquisa participante - busquei realizá-las de modo sistemático o suficiente para compor um estudo de caso de enfoque etnográfico (André, 1995). 
Os objetivos da pesquisa foram bastante modestos. Buscava, em cada uma das escolas, particularidades que auxiliassem a compreender de que modo tem ocorrido o ensino de Psicologia nas redes de ensino paulista. Embora tenha realizado a pesquisa em duas escolas distintas, em nenhum momento houve a pretensão de tomá-las como emblema de determinado conjunto de escolas. As generalizações realizadas decorrem exclusivamente da análise de cada caso em relação a seu contexto institucional, e as comparações efetuadas visam auxiliar a compreensão das realidades observadas.

As observações, em cada uma das visitas, foram anotadas em um diário de campo, posteriormente transcrito e analisado, e se referiram principalmente a: a) observação dentro da sala de aula, de atividades docentes, conteúdos ministrados, métodos didáticos empregados, relação entre professores e alunos, atividades dos alunos, rotinas estabelecidas (ou eventualmente quebradas), materiais utilizados, descrição do ambiente físico, relações entre alunos, intervenções burocráticas e também relações estabelecidas comigo na qualidade de pesquisadora; b) observação extraclasse, de relações entre professores, entre professores e escola, entre escola e alunos (por escola, leia-se o staff de funcionários da escola: diretores, secretários, inspetores, faxineiros, coordenadores etc.), localização da escola, acesso às dependências escolares, equipamentos oferecidos, rotina institucional. Nos tópicos que se seguem exponho a síntese do material pesquisado.

A observação (conforme Ezpeleta e Rockwell, 1986) reporta-se ao grau de interação entre o pesquisador e a realidade pesquisada, na medida em que o pesquisador exerce influência sobre essa realidade, mas também é influenciado por esta e por sua própria ação. Refere-se também, de modo especial em uma abordagem etnográfica, ao fundamento teórico que sustenta a existência de uma história não documentada, em que a dimensão cotidiana ganha força e expressão na apropriação que os indivíduos fazem das prescrições estatais e organizacionais. Nesta pesquisa, importou menos verificar o cumprimento de normativas ou instrumentos oficiais para a implementação do ensino de Psicologia na escola, e observar mais como o ensino de Psicologia se efetiva no cotidiano ${ }^{2}$ das escolas, como se insere na rotina da escola, as resistências e ressignificações postas por seus atores.

2. Contribui para a compreensão dos fenômenos escolares considerarmos o conceito de cotidiano à luz do pensamento de Agnes Heller (2000), que relativiza as escolhas do indivíduo particular na estrutura cotidiana à qual é lançado. 
Foram realizadas também algumas entrevistas com os docentes responsáveis pela disciplina de Psicologia, com docentes de outras disciplinas, coordenadores pedagógicos, direção da escola (apenas na escola da rede pública foi possível fazê-lo) e alunos. As entrevistas não foram dirigidas, de modo que os próprios entrevistados, em contato espontâneo com a pesquisadora, puderam tecer e desenvolver reflexões e considerações sobre sua prática cotidiana. Essas entrevistas não contaram com nenhum registro eletrônico; as falas dos entrevistados foram anotadas nos momentos em que se efetuava a transcrição dos diários, tão imediata e fidedignamente quanto possível. Desse modo busquei, ao longo da pesquisa, compreender melhor a realidade de cada um dos estabelecimentos de ensino observados, e, principalmente, como neles se desenvolvia o ensino de Psicologia, bem como os significados atribuídos por professores, escola e alunos para a disciplina cursada/ministrada.

\section{Duas escolas, realidades profundamente distintas}

A escola que aqui denominei $A$ é um renomado estabelecimento da rede privada de ensino da capital paulista, localizada em um bairro de classe média alta. Apesar de contar com uma ampla oferta de ônibus urbanos no entorno, a maior parte de seus alunos, quando não são moradores das redondezas, são buscados e trazidos por automóveis particulares, que se enfileiram nas ruas laterais graças a um planejado ordenamento de trânsito. A escola possuía seis turmas de primeiro ano no ensino médio, com cerca de 35 alunos cada e mensalidades que ultrapassavam então a casa dos mil reais (mais de 3 salários mínimos). A carga horária cumprida pelos alunos das salas de ensino médio observadas é de 28 horas semanais: das 7h20 da manhã à I 3 horas, com algumas disciplinas oferecidas no período da tarde. A estrutura física da escola, embora seja similar à escola da rede pública, possui condições de conservação muito diferentes da que denominei B. Nas salas de aula, são raros os casos de carteiras, cadeiras ou janelas quebradas. Os banheiros são limpos, têm sempre sabão e papel higiênico. As paredes contam com pintura nova, os jardins possuem flores.

A escola B pertence à rede pública estadual de ensino e se localiza em um bairro de periferia bastante distante do centro da cidade. O edifício da escola é amplo e relativamente novo. Embora bem conservado em comparação a outras 
escolas da rede pública, está longe de alcançar os padrões físicos da escola A: portas que não fecham, janelas quebradas, ausência de carteiras, lâmpadas queimadas, o que obriga os alunos a mudarem de sala; banheiros com vazamentos e tubulação exposta, sempre sujos, sem sabonete ou papel higiênico.

Para quem não é da região (caso de boa parte dos professores), o acesso à escola $B$ é difícil. A demora dos ônibus torna necessário caminhar cerca de 20 minutos até a estação de trem, por um caminho sinuoso, apenas parcialmente iluminado, com calçamento precário ou inexistente: a obrigação de seguir pela rua expõe os pedestres à sanha de motoristas que não hesitam trafegar em alta velocidade. A escola B é quase totalmente ladeada por um conjunto habitacional - Cohab - de altos e numerosos prédios, construído em um patamar superior em relação à escola. Isso torna facilmente transponíveis os muros que a rodeiam, evidenciando a patente ambiguidade na relação entre a escola e a sua clientela: ao mesmo tempo em que abriga a maioria dos alunos da escola, a Cohab abriga também delinquentes que a ameaçam, às vezes, alunos-delinquentes. Conta-se que ali funcionou o cativeiro de um empresário sequestrado; dali vieram e ali se esconderam os ladrões que, no semestre anterior furtaram todos os computadores de uso administrativo da escola.

Ambas as escolas pesquisadas eram totalmente muradas e contavam com controle da portaria no período de aulas. $O$ diferencial da escola A fica por conta de portões eletrônicos, câmeras de vídeo e segurança particular. Não foi percebida agressão aos equipamentos da escola A no período observado. Mas houve um episódio de furto: durante uma das aulas, uma aluna queixarase do desaparecimento de um porta-moedas contendo cerca de 70 reais que ela ganhara em um trabalho no fim de semana anterior. Nenhuma providência foi tomada por parte da escola, e o objeto não foi encontrado. Nenhum episódio de furto entre alunos foi relatado na escola B no período de presença em campo. Havia uma diferença significativa na relação entre funcionários e os alunos em um caso e noutro. Na escola B, havia uma clara diretriz no sentido de manter os alunos sob controle, evitando que eles saíssem da sala de aula, ou mesmo circulassem por todos os ambientes da escola (algumas portas eram mantidas permanentemente trancadas). Na escola A, as medidas de "proteção" diziam respeito sobretudo ao mundo exterior.

O recorte de classe e raça em ambas as escolas surgiu de diversas maneiras. Na escola A, apareceu no discurso da professora de Psicologia ao 
menos em duas ocasiões: numa delas, ao relatar um episódio, noticiado em um jornal de grande circulação, sobre o caso de uma mulher que guardava lixo compulsivamente em casa, a professora, numa ideológica associação entre doença mental, sujeira e pobreza, caracterizou a protagonista da história como uma "moradora de rua", mas a notícia, na verdade, se referia a uma moradora do abastado bairro do Itaim Bibi; noutra ocasião, em uma aula sobre fase fálica, o exemplo didático veio do relato de um diálogo do filho da professora com outra criança, em que esse afirmava o poder do "pênis israelense" (a despeito de todo sofrimento e discriminação sofridos pela população judaica ao longo da história, no contexto em que apareceu, o discurso da professora remetia à afirmação da superioridade de seu agrupamento em nosso meio, que teria sido perspicazmente percebida pelo filho pequeno). $\bigcirc$ assunto não foi discutido com os alunos. Nas duas salas de aula observadas na escola A, apenas um aluno negro compunha o corpo discente.

\section{As aulas de Psicologia}

A carga horária de Psicologia na escola A era de I h 15 min por semana, enquanto na escola B, de I h40min (equivalente a duas horas-aula). Na escola A, a disciplina de Psicologia se concentrava no primeiro ano do ensino médio, sob a justificativa de que constituía um conteúdo importante para a realização de projetos a serem desenvolvidos por alunos a partir do segundo ano, quando haveria a possibilidade de cursarem também a disciplina optativa "Psicologia Social". Na escola B, concentrava-se no terceiro ano do ensino médio, adequado à normativa da Secretaria Estadual de Educação à época.

$\mathrm{Na}$ escola A, o material didático, composto por textos, artigos de jornal e exercícios de apoio, era elaborado pela própria professora e reproduzido em folhas timbradas e impressas pela escola, assim distribuído a todos os alunos durante as aulas. Alguns exemplares permaneciam afixados em um mural. Eventualmente era utilizado o videocassete.

$\mathrm{Na}$ escola B não havia material didático. Os textos, quando existentes, eram passados na lousa e copiados pelos alunos, que dispendiam bastante tempo nessa tarefa. Nem todos possuíam caderno, e nem todos copiavam a matéria. A biblioteca - embora em funcionamento no período noturno, quando ocorria a observação -, era pequena, não possuía livros de Psicologia, e não era 
utilizada pela maioria dos professores da escola. Em algumas poucas situações foram distribuídos textos fotocopiados aos alunos, compostos de uma única página. A ausência de recursos didáticos é uma tônica na escola B: dificulta o ensino, furta tempo aos alunos, dificulta a aprendizagem.

$\mathrm{Na}$ escola A a lousa também figurava como recurso didático importante, mas não exclusivo. Assim, na lousa cabiam sínteses, esquemas, tabelas, ilustrações e enunciados de exercícios, não textos inteiros. Porém, as ocasiões em que a professora se dedicava a escrever na lousa, de modo concomitante às explicações, transformavam-se em momentos de dispersão da sala, de modo que, de bom grado, a professora aceitava a ajuda da estagiária para copiar na lousa matérias que ela trouxera previamente anotadas.

A disciplina dos alunos em sala de aula constituía um problema em ambos os casos. Na escola A, percebia-se dificuldade da professora em manter os alunos em silêncio durante as explicações e de envolvê-los nas atividades propostas. De acordo com a linha didática da escola, evitava-se tanto quanto possível reprimir o comportamento dos estudantes, o que frequentemente levava a professora a ver-se sem instrumental para lidar com os alunos. As tentativas de conseguir a atenção do grupo envolviam, inicialmente, a persuasão, e consecutivamente ameaças de que o aluno poderia ser retirado da sala (ameaças que eventualmente se cumpriam, e visavam claramente a ação sobre grupos específicos de alunos dispersos). Pude perceber que, em alguns casos, a professora mostrava dificuldade em adequar o tom de voz: ao mantê-lo elevado, mesmo diante de um eventual silêncio da classe, a tensão se mantinha e os alunos recomeçavam a conversar entre si. O ruído proveniente da avenida tampouco favorecia a promoção de um ambiente de concentração em classe. Manter a disciplina, o interesse e o envolvimento dos alunos constituía assim, o objetivo nem sempre alcançado. $\bigcirc$ que era considerado pela professora como insucesso, em parte, poderia ser atribuído à faixa etária em que se encontravam os alunos do primeiro ano, ainda pouco maduros para discutir os conteúdos abordados. Aquilo que era percebido como desinteresse, muitas vezes parecia-me, frequentemente, uma forma diferenciada de os alunos expressarem conteúdos aprendidos, os quais eram elaborados por meio de "piadas" ou verbalizações nem sempre ouvidas, e que eram vistos como bagunça. Em uma de nossas conversas, a professora acabou por revelar que nutria um excesso de expectativa em relação aos alunos e ao seu próprio desempenho. 
Para os trabalhos de sala de aula, como leitura de textos e realização de exercícios, os alunos muitas vezes conversavam entre si, e alguns deixavam a tarefa para ser concluída em casa. Cerca de metade da sala se envolvia ativamente na tarefa, aproveitando o tempo em sala para fazer perguntas e esclarecer, inclusive com a estagiária, algum ponto obscuro da matéria. Como as atividades valiam nota, num sistema em que a reprovação figurava como controle (a nota média mínima a ser alcançada era de 6 pontos), os alunos dificilmente se descuidavam da entrega dos exercícios, mesmo que com algum atraso, e discutiam vivamente cada questão durante a correção das avaliações.

$\mathrm{Na}$ escola B o modo de tratar a "indisciplina" era bastante diverso. $\mathrm{O}$ modelo adotado pela direção, bastante tradicional, conduzia a punições "mais fáceis", como expulsão de sala e advertência (o que não significava que essas punições fossem mais frequentes). Dentro de sala, porém, as conversas entre alunos eram corriqueiras e menos percebidas como problema. $\bigcirc$ limite para a bagunça era a porta, limiar da punição; dentro de sala de aula, era delegado ao professor o controle dos ruídos e dos alunos. A porta, porém, frequentemente estava quebrada. Assim, não raro surgia a figura do inspetor a ralhar com os alunos, que eram então punidos pela professora com novas atividades didáticas... dentro do pacto tácito estabelecido, o "prêmio" era ausência de atividades; enquanto a punição consistia em realizar efetivamente as tarefas didáticas. A mobilidade dos alunos no espaço dentro da sala era maior na escola $\mathrm{B}$, com alunos transitando entre as carteiras da sala para dirigir-se à professora ou aos demais colegas, o que, de certa forma, tornava o ambiente "mais leve", menos formal do que na escola $\mathrm{A}$, e facilitava o acesso dos alunos à professora. A relação entre professora e alunos era afetuosa, interessada. Apesar da grande quantidade de alunos que possuía, a professora se empenhava visivelmente em conhecer os alunos, também, em ouvir seus problemas e ocasionalmente oferecer conselhos. $\bigcirc$ que não implicava uma confusão de papéis, às vezes comum entre aqueles que exercem a clínica e o magistério concomitantemente (a professora da escola atuava exclusivamente como professora), mas sobretudo assumia um papel de "conselheira", bastante esperado pelos alunos. Uma situação compreensível diante de tantas carências. Era possível contar, entre os alunos de duas das salas de aula observadas (foram observadas, nesta escola, duas salas de ensino regular e duas salas de supletivo, estas compostas majoritariamente por adultos), ao menos três alunas, na faixa entre os 14 e os 
16 anos, em estágio avançado de gravidez. O "espaço" para os "conselhos" e as conversas informais antecedia o início da aula propriamente dito (após a realização da chamada), em que professora e alunos se cumprimentavam, esclareciam dúvidas sobre avaliações e informações burocráticas da escola, e também conversavam sobre si próprios.

A principal diferença entre as escolas A e B, porém, aquela que torna a primeira uma escola de ponta, enquanto a segunda conduz seus alunos à desilusão em relação a seu próprio aprendizado, é o conteúdo efetivamente ministrado. Na escola $A$, a despeito da carga horária comparativamente menor (35 minutos a menos por semana, em relação à escola B), os alunos puderam aprender, no pequeno período de observação, conteúdos da Psicanálise de forma sucinta (mas de modo algum superficial) e teoricamente irrepreensível. Na escola B, no entanto, a ausência de professores em todas as disciplinas, os constantes remanejamentos, a falta de materiais didáticos e de livros, os problemas de organização do trabalho docente, e mesmo de formação profissional produziram, ao final da observação, um apanhado superficial de conteúdos bastante criticáveis sob muitos aspectos, e queixas de alunos da pequena quantidade (e qualidade) de matéria que haviam aprendido. Em uma das situações em que a professora tivera de se ausentar da sala de aula, foram deixadas na lousa cinco questões, sobre diversos assuntos abordados ao longo do curso, para que os alunos respondessem (como estagiária, eu havia recebido a compulsória atribuição de administrar os alunos durante sua ausência). Diante da recusa de todos os alunos em realizar a atividade, fui descobrir a causa em seus cadernos: já avançados oito meses do início do ano letivo, um dos alunos mais dedicados da sala contava, na parte de seu caderno dedicada à Psicologia, três páginas de matéria escrita para consulta...

\section{CONTEÚDO DOS CURSOS}

Na escola A, os conteúdos da disciplina de Psicologia são divididos entre as principais correntes teóricas, behaviorismo, psicanálise e auto-ajuda (crítica do ponto de vista da ciência). A qualidade teórica do curso de Psicologia é alta: os conceitos, fundamentados na literatura original dos autores, são bem expostos e ilustrados com exemplos claros. Artigos de jornal são utilizados como forma de conferir atualidade à discussão. Questões cotidianas foram 
constantemente problematizadas e discutidas no curso, enriquecendo a compreensão da matéria e a própria reflexão do aluno. As diferentes teorias foram apresentadas pela professora como "teorias", e assim postas em relação às demais em diversos momentos das aulas. Ou seja, cada assunto foi trabalhado em classe em consonância com sua matriz epistemológica, em relação à qual foi possível compreendê-lo e criticá-lo.

$\mathrm{Na}$ escola $\mathrm{A}$, a partir do segundo ano, os alunos passariam a trabalhar em um miniprojeto de pesquisa, orientado por um dos professores da escola, que culminaria com a apresentação de um trabalho de conclusão. A justificativa para o ensino de Psicologia no primeiro ano baseava-se no fato de que esta disciplina constituía conteúdo fundamental para o desenvolvimento desse trabalho. A Psicologia comparece novamente como disciplina, sob o título de "Psicologia Social", no segundo ano letivo do colégio, que seria mais focalizado na realização das pesquisas (que, porém, não pudemos acompanhar).

No caso da escola $B$, os conteúdos eram extraídos todos de um único livro (Teles, 1999) voltado para o ensino médio, utilizado pela professora como material de apoio. $O$ livro, que tive a oportunidade de folhear, era de qualidade sofrível, e posso afirmar com pesar, seu uso comprometeu gravemente a qualidade teórica do curso ministrado. Um dos mais gritantes problemas do livro, que se reproduziu nas aulas, estava na apresentação da Psicologia como ciência una, descolada de seus autores e respectivas visões de mundo, sem diferenciação entre linhas de pensamento, sem conflitos teóricos, sem crítica. Os temas, separados em capítulos, exibiam classificações equivocadas e informações errôneas. Desse modo, discorria-se sobre as "divisões da consciência" em "ego, id e superego", ou se apresentava o desenvolvimento infantil como uma divisão estanque de habilidades (preensão, uso da linguagem, emprego de instrumentos etc.) associadas a faixas etárias pré-determinadas. Ou ainda, fato extraordinariamente grave, exibia-se uma visão estigmatizadora da doença mental, apresentando-a como um conjunto de patologias de sintomas protocolares.

A realidade profissional das duas professoras imprimia suas marcas em cada um dos cursos. A professora da escola A atuava, paralelamente ao trabaIho docente, também em consultório particular, o que se refletia na visão de Psicologia transmitida - sobretudo associada ao atendimento clínico - e nos exemplos utilizados. A própria predominância da Psicanálise como conteúdo curricular confirma essa visão. Especialmente nas atividades didáticas realiza- 
das, contudo, a Psicologia surgia também como instrumental para a leitura de fenômenos sociais contemporâneos (por exemplo, quando se discutia sobre a tendência de prolongamento da adolescência nos dias atuais).

A professora da escola B, em paralelo, ministrava também aulas de Filosofia, em virtude do curso superior de Filosofia que já cursava, às próprias expensas, como forma de obter a atribuição de um número maior de aulas. Frequentemente, então, os conteúdos das duas disciplinas se misturavam, quando se tratava da mesma turma. Se por um lado, as aulas de Psicologia ganharam maior espaço para reflexão dos alunos em sala de aula, inclusive com maior abertura didática, por outro, ambas as disciplinas, Psicologia e Filosofia, perderam conteúdo, do ponto de vista formal, e as atividades didáticas acabavam mecanicamente repetidas em turmas diversas.

Para esta professora, conforme expôs em uma das entrevistas, o aumento da carga horária de Sociologia e Filosofia em detrimento da Psicologia seria positivo (embora, segundo ela, não verdadeiramente intencionado pela Secretaria da Educação), por representar abertura de espaço para a crítica dentro do currículo do ensino médio, característica não contemplada pela disciplina de Psicologia. Sua fala reiterava uma visão instrumental da Psicologia, fato, neste caso, fartamente demonstrado ao longo de seu curso. Nenhuma das duas professoras demonstrou preocupação direta com o advento da nova resolução do CNE. Entretanto, a preocupação aparecia nas entrelinhas. Na escola $A$, no momento em que a professora questiona o modo como será incluída a Sociologia na grade curricular a partir do próximo ano, na escola B, acredito que a própria iniciativa da professora em buscar complementação à sua formação seja indicador de reação à medida ${ }^{3}$.

\section{DISCUTINDO A PSICOLOGIA NO ENSINO MÉDIO}

Embora tenhamos estudado duas escolas de um mesmo sistema de ensino, fica nítido, mesmo que não conhecêssemos a priori sua condição, que

3. Um outro fator a ser considerado em relação a esta questão refere-se à maior facilidade para o professor conseguir (e manter) aulas em uma mesma escola quando possui habilitação para o ensino de duas disciplinas. Uma vez que a quantidade de aulas de Psicologia é pequena, para preencher sua grade o professor acaba por assumir aulas em diversas escolas, perdendo tempo e dinheiro em deslocamentos que não são reembolsados pelo estado. 
se trata de escolas efetivamente pertencentes a redes de ensino diversas. Não estou com isso, reitero, tomando qualquer das escolas estudadas como caso exemplar, pois, de resto, além dos problemas observados em ambos os casos, sabemos que, especialmente na rede privada, a situação e a qualidade de ensino em diferentes estabelecimentos variam enormemente. É importante, porém, para a discussão à qual nos propomos, guardar as devidas considerações entre realidades educacionais tão distintas como as expostas aqui.

O ensino médio traz como premissa, apontada entre outras pela LDB, a preocupação com a formação do cidadão, por um lado, e a preparação para o mundo do trabalho, por outro. Os alunos da escola A não estão preocupados, contudo, em encontrar um emprego no momento em que deixarem a escola; estão, sim, interessados, na sua grande maioria, em alcançar vaga em uma boa universidade, uma vez que possuem tempo maior para se formar antes de ingressar no mercado de trabalho. Aos 16 anos, contudo, muitos já irão votar; aos 18, muitos obterão carteiras de habilitação; ao iniciarem seus estudos em uma faculdade, independente do curso que venham a escolher, muito provavelmente será esperado deles que possuam formação cultural e científica necessária para compreender os debates ali travados, para se posicionar diante de problemas, para alavancar estudos específicos, ou mesmo que os habilitem a consumir os produtos culturais oferecidos pela metrópole e/ou o meio acadêmico. Estes são alguns dos sentidos para a formação humanista e generalista recebida na escola que cursavam.

Para os alunos da escola B, embora o preceito legal se mantenha inalterado, as expectativas postas são de todo diversas. Até os melhores alunos com quem tive oportunidade de conversar não tencionavam prestar vestibular para universidades públicas, mesmo sabendo que possuem isenção de taxa de inscrição: não se atrevem, percebem suas chances como infinitamente pequenas, sentem-se fracos. Não se trata de um delírio. Eles sabem que a qualidade do ensino que receberam não os coloca em patamar de comparação diante das melhores escolas. Tentarão, nesse caso, ingressar em um curso técnico, ou em um curso universitário de formação breve e caráter tecnicista, para entrar no mercado de trabalho o mais rápido possível e obter assim retorno financeiro mais imediato. Seus sonhos se transformam em hobbies. Sua condição financeira não lhes permite esperar, "dando-se o luxo" de prolongar a formação por mais tempo. 
Ambos os cenários se aproximam quando tomamos em consideração aspectos tão contraditórios e, ao mesmo tempo, tão esclarecedores nas duas escolas. Se o desejo por uma formação de caráter mais crítico comparece na escola B, sem que, entretanto, venha acompanhada de conteúdos formais que tragam embasamento à reflexão, na escola $\mathrm{A}$, conteúdos são irretocavelmente transmitidos, sem que, contudo, sejam articulados com a realidade social, cultural e econômica em que foram engendrados; dissociados do contexto que os produziu, sua abordagem não se presta à crítica, não auxilia os alunos a perceberem verdadeiramente o mundo ao redor de si, postos fora os filtros da estereotipia construída pela elite que lhes nutre. Como exemplo ligeiro, não se pode contestar, sob o horizonte de uma formação humanista, a importância de um aluno saber corretamente o que pensava Freud, mesmo no caso de este aluno futuramente vir a escolher Engenharia como curso superior. Entretanto, quando nos remetemos especialmente à postura da professora "como representante de uma determinada classe" em sala de aula, verificamos que o potencial crítico da Psicologia para a leitura da realidade perde em absoluto seu espaço ali. Ganha lugar o conhecimento como instrumento de disputa (Bourdieu, 1998), a compor o "capital cultural" de uma classe minoritária.

Realidades escolares aparentemente tão distintas se afastam e se complementam, ocupando lados opostos no mesmo cenário que thes oferece explicação e sentido. Desse modo, a escola vai bem cumprindo sua função de mostrar aos aprendizes qual papel social lhes está destinado. Ao refletirmos sobre a pertinência da Psicologia como conteúdo necessário ou adequado para o ensino médio, não podemos perder de vista essas considerações.

O posicionamento crítico da professora na escola B mostrou-se insuficiente para assegurar que seus alunos obtivessem do curso elementos para o exercício reflexivo tanto dentro da escola quanto para enfrentar os embates sociais e econômicos que o mundo impõe. Isso não se refere apenas à qualidade de ensino na escola $B$, que de resto é mesmo ruim, mas principalmente à ausência de melhor compreensão acerca do papel da Psicologia como conteúdo ali inserido. Ou, dizendo melhor: a disciplina de Psicologia preenche naquela escola um papel curricular recusado pela professora, sem que, entretanto, ela (ou outros tantos atores institucionais) tenha sido capaz de propor um novo, mais bem sintonizado às necessidades dos alunos e do sentido que o professor desejava imprimir à sua tarefa. Desprovido de meios que the permitam refletir 
e mesmo interferir de muitos modos no próprio trabalho, o professor acaba por não assumir verdadeira responsabilidade pelo curso que ministra.

Uma visão pragmatista da Psicologia contamina as aulas ministradas na escola B, como se a via de sua aplicabilidade fosse a única permitida dentro do sistema de um ensino voltado às classes populares. Se esta via se mostra infértil para a professora da escola $B$, e também para seus alunos, uma grande dificuldade, contudo, aparece no momento de buscar na disciplina conteúdos que permitam refletir sobre a condição humana, suas relações, fatores que determinam e libertam o ser humano, enfim, sobre aquilo que constitui, em última instância, o próprio objeto da Psicologia. No caso, pareceu mais fácil mudar o argumento, e realizar a crítica por meio de questões já tradicionalmente formuladas no contexto educacional brasileiro, e que compareciam, paradoxalmente, com grau menor de dúvida e grau maior de delimitação, na disciplina de Filosofia (algumas das quais também pude acompanhar).

Essa não é uma discussão simples, de modo que não à toa grande parte dos psicólogos têm-se esquivado dela, com muitos prejuízos para todos os lados: professores que perdem a função, outros que têm de arcar com mais uma formação adicional, alunos que não aprendem e psicólogos que perdem a chance de compreender melhor seu papel e refletir a respeito da realidade em que se inserem e de seu exercício profissional.

Nesse sentido, não podemos perder de vista a trajetória que a Psicologia historicamente tem desenhado no país. Se a partir dos anos 80, principalmente, setores da Psicologia puderam inaugurar outros rumos para a pesquisa e o ensino de Psicologia, voltados à transformação da realidade social e econômica do país, esta não foi - e talvez ainda não seja - uma corrente hegemônica no campo Psi. Particularmente na área da Psicologia Escolar, justamente dentro da escola (Patto, 1993) e dos cursos de formação superior em Psicologia (Souza, 1996), é que ainda se fazem sentir os ecos das teorias raciais, da carência cultural, de explicações medicalizantes e outras, encarregadas de responsabilizar alunos pobres pelo fracasso do sistema escolar brasileiro. Ecos que ainda hoje reverberam nas paredes da disciplina.

Importa lembrar que ainda há muito a se fazer para melhorar o ensino superior de Psicologia (Clasta, 2003). Uma formação ruim terá como consequência inevitável um ensino ruim, cuja rota dificilmente será corrigida por programas de formação em serviço (que, de resto, nunca foram oferecidos 
aos professores de Psicologia da rede estadual paulista, desde que a disciplina Psicologia voltou a compor o currículo do ensino médio).

A inclusão da Psicologia no ensino médio não deve ser automática. Tampouco a Filosofia e a Sociologia. No caso da Sociologia, sabemos que os riscos de ver a disciplina se transformar em mais um espaço depósitário de informações instrumentais é muito mais presente hoje do que talvez imaginasse Florestan Fernandes quando defendia a sua adoção nos idos de 1955.

Não basta, portanto, a mera presença de um projeto qual seja de Psicologia para o ensino médio. Educadores e psicólogos devem aproveitar, então, a deixa ora aberta pela rede de debates que os psicólogos começam a tecer para discutir o que dentro da Psicologia importa como conteúdo fundamental à formação do homem e do cidadão em nossos dias. Talvez, nesta discussão, possamos descobrir que o potencial da Psicologia para a "promoção da cidadania", como reza a LDB, ou melhor, para a emancipação de nossos aprendizes, seja maior do que inicialmente se supunha.

\section{REFERÊNCIAS BIBLIOGRÁFICAS}

ANDRÉ, M. E. D. A. Etnografia da prática escolar. Campinas: Papirus, 1995.

AZZI, R.; SOLLIGO, A. F. Psicologia no ensino médio: desafios e perspectivas. São Paulo: Conselho Regional de Psicologia, 2008.

BOURDIEU, P. A Miséria do mundo. Petrópolis: Vozes, 1998.

BRASIL. Leis e decretos. Subchefia para Assuntos Jurídicos: estabelece as diretrizes e bases da educação nacional. Diário Oficial da União. Brasília, 20 dez. 1996. Disponível em: www. planalto.gov.br/ccivil_03/Leis/L9394.htm. Acesso em: 2 out. 2008.

Lein. I I.684, de 2008: altera o art. 36 da Lein. 9.394, de 20 de dezembro de 1996, que estabelece as diretrizes e bases da educação nacional, para incluir a Filosofia e a Sociologia como disciplinas obrigatórias nos currículos do ensino médio. Diário Oficial da União, Brasília, 3 jun. 2008. Disponível em: www.planalto.gov.br/ccivil_03/Ato 200720 I0/2008/Lei/L I 1684.htm. Acesso em: 2 out. 2008.

Discutindo uma concepção curricular para o ensino médio: documento preliminar. Brasilia: MEC/Semtec, 1997.

Parâmetros curriculares nacionais para o ensino médio, parte I: bases Legais.

Brasilia: MEC, 1999. 
BRASIL. Ministério da Educação. Conselho Nacional de Educação. Câmara de Educação Básica. Parecer n. 38/2006: altera o artigo 10 da Resolução CNE/CEB n. 3/98, que institui as Diretrizes Curriculares Nacionais para o ensino médio. Diário Oficial da União, Brasília, n. I 55, seção I, p.9, I 4 ago. 2006.

CAPALBO, C. Situação do ensino de filosofia no Brasil: relatório elaborado para a Unesco. Disponível em: http://www.prograd.ufpr.br/nesef/artigos/novo/Ens.\%20Filosofia.relat\%F3rio\%20 finalUNESCO.doc. Acesso em: 27 out. 2006.

CARONE, I. A Psicologia tem paradigmas? São Paulo: Casa do Psicólogo, 2003.

CLASTA, N. C. R. A. A Formação dos psicólogos na década de 1990: uma leitura frankfurtiana. In: NENEVÉ, M.; PROENÇA, M.; RIBEIRO, R. (orgs.) Psicologia e saúde na Amazônia: pesquisa e realidade brasileira. São Paulo: Casa do Psicólogo, 2003. p.39-64.

EZPELETA, J.; ROCKWELL, E. Pesquisa participante. São Paulo: Cortez, 1986.

HELLER, A. O Cotidiano e a história. 6. ed. São Paulo: Paz e Terra, 2000. [Trad.: C. N. Coutinho e L. Konder]

HORKHEIMER, M. Teoria tradicional e teoria crítica. In: BENJAMIN, W. et al. Textos escolhidos. São Paulo: Abril Cultural, 1980. p. 1 17-154.

PATTO, M. H. S. A Produção do fracasso escolar: histórias de submissão e rebeldia. São Paulo: T. A. Queiroz, 1993.

ROMAN, M. D. Neoliberalismo, política educacional e ideologia: as ilusões da neutralidade da pedagogia como técnica. Psicologia USP, São Paulo, v. I0, n.2, p. I53-187, 1999.

SÃO PAULO (Estado). Secretaria da Educação. Conselho Estadual de Educação. Indicação n. 53/05: orientação ao Sistema Estadual de Ensino a respeito da qualificação necessária dos docentes para ministrar aulas das disciplinas do currículo da educação básica. Diário Oficial do Estado de São Paulo, 16 dez. 2005. Disponível em: http://ise.edunet.sp.gov.br/sislegis/pesqorient_ano.asp.Acesso em: 2 out. 2008.

Secretaria da Educação. Resolução n. 92/07: estabelece diretrizes para a organização curricular do ensino médio e fundamental nas escolas estaduais. Diário Oficial do Estado de São Paulo, 9 dez. 2007. Disponível em: http://ise.edunet.sp.gov.br/sislegis/pesqorient_ano. asp? Ano $=2007$. Acesso em: 2 out. 2008.

Secretaria da Educação. Resolução n.6/05: estabelece diretrizes para a organização curricular do ensino médio, no período diurno, nas escolas estaduais. Diário Oficial do Estado de São Paulo, 28 jan. 2005a. Disponível em: http://ise.edunet.sp.gov.br/sislegis/pesqorient_ano. asp? Ano = 2005. Acesso em: 2 out. 2008. 
Secretaria da Educação. Resolução n.236/83: dispõe sobre as diretrizes para reorganização do ensino de $2^{\circ}$ grau nas escolas da rede estadual. Diário Oficial do Estado de São Paulo, 3 out. 1983. Disponível em: http://ise.edunet.sp.gov.br/sislegis/pesqorient_ano.asp. Acesso em: 2 out. 2008.

SOUZA, M. P. R. A Queixa escolar e a formação do psicólogo. São Paulo, 1996. Tese (dout.) Instituto de Psicologia da Universidade de São Paulo.

TELES, A. X. Psicologia moderna. 35. ed. São Paulo: Ática, 1999.

Recebido em: janeiro 2007

Aprovado para publicação em: outubro 2008 